\title{
Crítica à Alteração da Lei Maria da Penha: Tutela e Responsabilidade
}

\author{
Paula Dias Moreira Penna ${ }^{1}$ \\ Fábio Roberto Rodrigues Belo \\ Universidade Federal de Minas Gerais
}

\begin{abstract}
RESUMO: A Lei Maria da Penha, ao transformar os crimes contra a mulher em crimes de ação penal pública incondicionada, torna o processo contra o agressor uma iniciativa do Estado, independentemente da vontade da mulher vítima da agressão. Analisada a partir do método hermenêutico crítico e da psicanálise, sustentamos que tal mudança produz uma desresponsabilização do sujeito frente ao seu masoquismo e sustenta uma dobra ideológica que trata a mulher como infantil e passiva, naturalizando uma situação histórico-libidinal. Por fim, a conclusão apresenta a hipótese de que tal mudança na lei é perniciosa ao objetivo de criar condições sociais e libidinais para que a mulher possa responsabilizar-se, reconhecendo os fatores inconscientes envolvidos na situação de agressão.
\end{abstract}

Palavras-chave: masoquismo, atividade-passividade, responsabilidade, direito penal, Lei Maria da Penha

\section{Review of the Amendments on Maria da Penha Law: Protection and Accountability}

\begin{abstract}
The Maria da Penha Law, after being changed into hardcore criminal action, makes the process against the offender a State initiative, independent of the will of the woman who suffered aggression. Analysed from critical hermeneutical method and psyschoanalysis, we support that such change creates an un-accountability of the subject facing his/her masochism and supports an ideological bending which treats the woman as childish and passive, transforming a historical-libidinal situation into a natural situation.. We conclude defending the hypothesis of such change in the law being pernicious to the objective of creating social and libidinal conditions for the woman to take responsibility for herself, acknowledging the unconscious factors involved in the aggression situation.
\end{abstract}

Keywords: masochism, activity-passivity, responsibility, criminal law, Maria da Penha law

\section{A Lei Maria da Penha}

A Lei $\mathrm{n}^{\circ} 11.340$, de 07 de agosto de 2006, conhecida como Lei Maria da Penha, foi criada para coibir e prevenir a violência doméstica e familiar contra a mulher. A lei considera violência qualquer ação ou omissão que possa causar morte, lesão, sofrimento físico e psicológico, além de dano moral e patrimonial.

Até fevereiro de 2012, a Lei Maria da Penha garantia à mulher o direito de representar ou não contra o parceiro agressor (ação penal pública condicionada à representação). Tratava-se de um dispositivo legal ao qual o sujeito podia recorrer, sendo proveniente de uma decisão na qual estava implicado. Define-se a representação como:

a manifestação de vontade do ofendido ou de quem tenha qualidade para representá-lo, visando à instauração da ação penal contra seu ofensor. A representação, em determinadas ações, constitui condição de procedibilidade para que o Ministério Público possa iniciar a ação penal. (Bitencourt, 2005, p. 335)

Entretanto, em 09 de fevereiro de 2012, o Supremo Tribunal Federal (STF) decidiu tornar os crimes previstos na Lei Maria da Penha como de ação penal pública incondicionada (STF,

1 Endereço para correspondência: Universidade Federal de Minas Gerais, Faculdade de Filosofia e Ciências Humanas, Gabinete 4032, Av. Antônio Carlos, 6627, Pampulha, Belo Horizonte, MG, Brasil. CEP: 31.270-901.E-mail: popsdiasmp@yahoo.com.br
2012). A ação penal pública incondicionada se caracteriza por ser uma denúncia promovida pelo Ministério Público (representante do Estado nas ações públicas). Essa iniciativa é "incondicionada" porque não depende nem se subordina a nenhuma condição ou vontade da pessoa atingida, sendo irrelevante a oposição desta ou de quem quer que seja.

Em 2014, a Lei Maria da Penha completou 08 anos de sua publicação. Embora seja relativamente nova, ela foi citada pela Organização das Nações Unidas (ONU) - em recente relatório sobre a situação das mulheres no mundo (BBC BRASIL, 2011) - como uma das iniciativas pioneiras na defesa dos direitos das mulheres. Um dos aspectos mais valorizados no relatório da $\mathrm{ONU}$ foi o fato de a lei apresentar em seu bojo uma série de medidas protetivas de urgência, que restringem os atos do agressor: obriga-o a afastar-se do lar, proíbe-o de se aproximar da ofendida, suspende seu porte de armas, etc.

Pesquisa publicada pela Fundação Perseu Abramo em 2011 revela que uma em cada cinco brasileiras afirma já ter sofrido algum tipo de violência doméstica. Esse índice não sofreu nenhuma alteração de 2001 a 2011 (Fundação Perseu Abramo, 2011). Com a promulgação da lei, o número de denúncias aumentou efetivamente; no entanto, do ponto de vista da prevenção, não houve mudança sensível. A lei favoreceu a denúncia, mas nem por isso a violência diminuiu.

Abordaremos os efeitos dessa mudança jurídica a partir dos pressupostos metodológicos da Psicanálise e da 
Hermenêutica Crítica. Se a lei não funciona por si só para prevenir a violência e para reduzir sua incidência, tornase necessária uma análise que tome como ponto central a posição dos sujeitos e a significação da violência para as mulheres envolvidas. E se a questão é pensar a posição do sujeito, podemos nos valer dos preceitos da psicanálise, que tem como interesse o sujeito em sua relação com a cultura. A Psicanálise considera o sujeito responsável por seus atos; ele está implicado definitivamente na construção de sua subjetividade, até mesmo quando se trata de seu pensamento inconsciente. Além disso, a Hermenêutica Crítica sugere analisar textos, discursos e produções culturais (como a mudança jurídica em exame) como fundamentalmente mediados por relações de poder estabelecidas social e historicamente (Kincheloe \& McLaren, 2006)

\section{As Mulheres e a Lei}

Para iniciar nossa reflexão, é importante contextualizar o lugar das mulheres na sociedade ocidental por meio de uma breve retomada sócio-histórica. A historiadora francesa Michelle Perrot (2005) faz uma análise sobre o percurso da mulher na história desde o período oitocentista. Segundo ela, trata-se de um percurso de silêncio: silêncio nas assembleias políticas povoadas de homens eloquentes; silêncio no espaço público onde sua intervenção coletiva é assimilada à histeria do grito e a uma atitude barulhenta demais; silêncio até mesmo na vida privada. Afastadas pelas obrigações mundanas que ordenavam que as mulheres evitassem os assuntos mais "quentes", como a política, elas eram consideradas suscetíveis de "perturbar a convivialidade" ( $p$. 10) e destinadas a se limitar às conveniências da polidez no mais profundo silêncio.

A irrupção da presença e da fala feminina em locais que eram até então proibidos é uma inovação do final do século XIX e estoura no século XX. O empenho do movimento feminista em fazer-se compreender como um movimento de luta contra a figura da mulher dominada e oprimida, de características inatas fragilizadas, vai ao encontro da compreensão de que a mulher é fruto de elaborações sociais historicamente construídas. A mulher foi escrita e falada pelos homens porque elas aparecem menos no espaço público, objeto maior da observação e da narrativa, fala-se pouco delas e ainda menos caso quem faça o relato seja um homem que se acomoda com uma costumeira ausência, serve-se de um masculino universal, de estereótipos globalizantes ou da suposta unicidade de um gênero: a mulher. (Perrot, 2005, p. 11)

Tendo em vista que o nosso objeto de estudo é a mulher em situação de violência doméstica na interface da Psicanálise com o Direito, é preciso lembrar que, desde os mais remotos manuais e códigos jurídicos escritos, há registros de leis que colocavam as mulheres em posição submissa frente à virilidade masculina. A título de exemplo, destacamos a legislação brasileira. O primeiro Código Civil, promulgado em 1916 e revogado no ano de 2002, determinava, em seu artigo $6^{\circ}$, que "as mulheres casadas, enquanto subsistir a sociedade conjugal, são relativamente incapazes frente a alguns atos da vida civil" (Lei Federal n. 3.071, de $1^{\circ}$ de Janeiro de 1916). Elas precisavam de autorização do marido, entre outras coisas, para trabalhar. Sabemos que houve vários avanços na legislação civil brasileira, mas, apesar das mudanças das leis, algumas mulheres continuam em uma relação de dominação com o parceiro, incluindo-se aí, frequentemente, as cenas de agressão. Por essa razão, fez-se necessária a promulgação da Lei Maria da Penha, com o intuito de proteger as mulheres que, ainda nos dias de hoje, sofrem com a agressão conjugal. Essa lei teve uma importância singular no panorama legislativo brasileiro. No entanto, sua alteração recente nos coloca a questão: a decisão do STF de transformar os crimes previstos na Lei Maria da Penha em ação penal pública incondicionada levaria à desimplicação das mulheres na questão que as atinge, desresponsabilizando-as na medida em que estaria sendo retirada delas a chance de se posicionar como sujeito do desejo?

\section{As Mulheres, o Masoquismo e a Passividade}

A família moderna vem sofrendo profundas modificações, embora continue com seu papel primordial de transmitir cultura. No entanto, a violência insiste e o mal-estar entre os parceiros persiste, levando-nos a questionar a posição das mulheres em situação de violência doméstica nesse contexto. (Penna \& Leão, 2014). As razões pelas quais as agressões domésticas começam são múltiplas, mas a posição que algumas mulheres assumem frente a esse fato é algo importante a ser considerado. Por que, mesmo após as primeiras agressões, algumas mulheres se mantêm dentro de casa, convivendo com a violência?

Kehl (2013) lembra que a Psicanálise se serve da dialética entre o público e o privado para pensar a diferença sexual. Ela ressalta o peso da "insignificância pública das mulheres" (p. 3) na dependência absoluta ao parceiro:

É a representação pública da masculinidade e a potência de que um homem dispõe no espaço público que lhe confirma a ilusão de falicidade, ainda que imaginariamente ela se apoie sobre a posse de um pênis. É a insignificância pública das mulheres que faz valer a ilusão de sua "maiscastração", ainda que a ausência do pênis contribua para consolidar esta fantasia. Foi em razão da insignificância, da impotência milenar das mulheres no espaço público, que Freud veio a observar a confusão fantasmática de suas histéricas, que superpunham demanda de falo e demanda de pênis, e cujo único consolo era a conquista do falo/filho que as condenava à dependência absoluta de fazer-se amar, ou pelo menos desejar, por um homem. (p.3)

Na busca desse "consolo" frente a uma ausência de resposta para o feminino e de sua "impotência", suportar a agressão calada seria uma forma de existir como mulher? $\mathrm{Na}$ relação com o parceiro, a mulher pode encontrar um lugar que a acomoda como objeto de gozo, objeto a ser batido, a partir de uma posição passiva.

A posição passiva articula-se ao que Freud (1924/2006c) desenvolveu sobre o masoquismo a partir da teoria da pulsão de morte. Ele afirma que o masoquismo apresenta-se sob três formas de manifestação: como condição imposta à excitação sexual, como expressão da natureza feminina e como norma de comportamento. Assim, Freud define o masoquismo 
erógeno e outros dois derivados dele: o masoquismo feminino e o masoquismo moral.

Interessa-nos aqui discorrer acerca do masoquismo feminino, que, segundo Freud (1924/2006c), está ligado a uma posição feminina associada ao ser castrado, ser copulado, dar a luz a um bebê. $\mathrm{O}$ autor é incisivo em dizer que o masoquismo feminino não se manifesta apenas em mulheres, mas diz respeito a uma posição passiva, o que ele considera como sendo o papel das mulheres na relação sexual.

Essa forma de masoquismo estaria ligada a inúmeras características da vida infantil, superpondo, assim, aspectos do infantil e do feminino, revelando a fantasia feminina de ser tratada como uma criança pequena e desamparada. Dessa forma, Freud (1924/2006c) liga a mulher à passividade e inevitavelmente, infantiliza-a. Ele considera o sentimento de culpabilidade que tem sua gênese nos períodos remotos da infância, relacionados à masturbação infantil. Ele toca um ponto da angústia de castração, que abre caminho para o gozo. O paciente recusa-se a fazer uma conexão entre seu sofrimento e seu sentimento de culpa, e a dor satisfaz sua necessidade de castigo, entrando no que Freud chamou de masoquismo moral.

Parece haver uma aproximação constante na obra de Freud entre os termos feminino, passividade e mulher. É importante nos debruçarmos sobre a história dessa associação de termos, que talvez não seja sem consequência para uma concepção psicanalítica sobre as mulheres.

Freud (1925/2006e) alega que a diferença entre o desenvolvimento sexual da menina e do menino é uma consequência da distinção anatômica entre seus órgãos genitais e da situação psíquica aí envolvida, na medida em que "corresponde à diferença entre uma castração que foi executada e outra que simplesmente foi ameaçada" (p. 285). Considerando a fase pré-edipiana nas meninas, Freud realça a secundariedade do complexo de Édipo feminino, na medida em que o complexo de castração o precede e o prepara. Afirma que, "enquanto nos meninos, o complexo de Édipo é destruído pelo complexo de castração; nas meninas, ele se faz possível e é introduzido através do complexo de castração" (p. 285). Para o menino, o reconhecimento de que existem seres a quem falta um órgão impõe o temor à castração e o leva a abrir mão de sua relação amorosa com a mãe, ou seja, de seu complexo de Édipo. Já a menina, ao constatar a mesma falta, tira suas conclusões: ela vê, sabe que não tem e quer ter o órgão sexual. Sabe também que a mãe não o tem. É assim que ela afrouxa suas relações amorosas com a mãe e se endereça ao pai como objeto de amor. É o complexo de castração que permite a sua entrada no complexo de Édipo. Quer receber do pai o que lhe falta, assim como aconteceu com sua mãe. Para Freud, o complexo de castração inibe e limita a masculinidade e incentiva a feminilidade.

Freud (1924/2006d) já havia afirmado que as coisas relativas à organização fálica, o complexo de Édipo e o complexo de castração na menina "não podem ser as mesmas como são nos meninos" (p. 197). Acrescenta: "Aqui, a exigência feminista de direitos iguais para os sexos não nos leva muito longe, pois a distinção morfológica está fadada a encontrar expressão em diferenças de desenvolvimento psíquico. 'A anatomia é o destino', para variar um dito de Napoleão” (Freud, 1900/2006a, p. 197).
É bom ressaltar que, quando Freud (1900/2006a) conclui que "a anatomia é o destino", ele está fazendo uma junção entre o psíquico e o somático. A diferença é uma consequência da anatomia no que esta determina, pelo juízo que a criança efetua, uma situação psíquica diferente: ser castrado e o temor de ser castrado. A anatomia é destinada a partir de uma história libidinal.

No decorrer do trabalho analítico, Freud (1933/2006g) pôde observar fatores que relativizam o peso dado à anatomia. Ele relata que

nem sempre é fácil distinguir o que se deveria atribuir à influência da função sexual e o que atribuir à educação social. Assim, atribuímos à feminilidade maior quantidade de narcisismo, que também afeta a escolha objetal da mulher, de modo que, para ela, ser amada é uma necessidade mais forte que amar. (p. 131)

Reconhecendo a diferença entre o complexo de Édipo nos meninos e nas meninas, Freud (1925/2006e) discorda da proposta dos/das feministas quanto à igualdade dos dois sexos e ressalta as construções teóricas relativas ao que poderia se considerar "masculinidade" e "feminilidade" puras.

Não devemos nos permitir ser desviados de tais conclusões pelas negações dos feministas, que estão ansiosos por nos forçar a encarar os dois sexos como completamente iguais em posição e valor; mas, naturalmente, concordaremos de boa vontade que a maioria dos homens também está muito aquém do ideal masculino e que todos os indivíduos humanos, em resultado de sua disposição bissexual e da herança cruzada, combinam em si características tanto masculinas quanto femininas, de maneira que a masculinidade e a feminilidade puras permanecem sendo construções teóricas de conteúdo incerto. (p. 286)Valendo-se da diferença entre os parceiros nas relações amorosas, Freud (1930/2006f) ressalta a ligação entre as pulsões de vida e de morte presentes nas relações eróticas, que, além de seus componentes sádicos próprios, são frequentemente acompanhadas de uma cota de franca tendência agressiva. Ele exemplifica essa ligação com a seguinte passagem: "O objeto de amor nem sempre demonstrará tanta compreensão e tolerância com estas complicações quanto aquela camponesa que se lamenta que seu marido deixou de amá-la porque faz uma semana que não a espanca" (p. 115).

Ser espancada pode permitir uma forma de satisfação - mesmo que seja inconsciente - e está além do princípio do prazer. Marcada pela passividade e pela insatisfação - a eterna sensação de que lhe falta algo -, algumas mulheres em situação de violência doméstica podem vir a sustentar o sofrimento e o lugar de vítima, sem se interrogar por sua participação na desordem da qual se queixam.

A equiparação entre a posição masoquista e a posição feminina não significa, no entanto, que as mulheres devam se reconhecer "por natureza" como masoquistas; essa equiparação, segundo Freud (1924/2006c), não diz respeito às mulheres, mas à passividade de qualquer sujeito. Ou seja: se as mulheres não são masoquistas por natureza ou se o feminino não se liga diretamente ao masoquismo, podemos pensar que essa posição ocupada por algumas mulheres é singular e subjetiva. A nossa crítica é que, ao ligar o feminino à passividade e ao masoquismo, Freud, por ter vivido em uma sociedade fortemente patriarcal, pode ter produzido um 
discurso que pode contribuir para que algumas mulheres se identifiquem e se coloquem nesse lugar de submissão e de dominação característico da situação de violência doméstica.

A cultura europeia dos séculos XVIII e XIX produziu uma série de discursos para promover uma adequação entre a mulher e o conjunto de funções e atributos denominados "feminilidade". Entre eles, destaca-se atributos ligados à sua condição física e capacidade procriadora, destinando-a a ocupar como um ser passivo um único lugar social: a família e o espaço doméstico; e um único destino: a maternidade. (Kehl, 2008).

Mesmo diante da reiterada advertência de que a passividade pertence a qualquer sujeito, nós buscamos evitar essa dobra ideológica reforçando a ideia de que o que está em questão no masoquismo é a erotização da passividade - e não uma suposta "posição feminina". Criticar a equivalência entre feminino e passividade é um passo importante para desatrelar a condição social das mulheres àquilo que historicamente tem sido atribuído ao feminino: passividade, dor, perversidade e loucura (Carvalho, 2012).

\section{A Lei que Desresponsabiliza}

A questão que se coloca, no que diz respeito a uma ação penal pública incondicionada, é se, nesse caso, o Estado como legislador e aplicador das leis não viria reforçar a posição de objeto que a mulher pode vir a ocupar. Se uma ação se faz independentemente do assentimento do envolvido, estaríamos na dimensão da irresponsabilidade, assim como se consideram a criança e o louco, que são protegidos integralmente pelos estatutos legais como o Estatuto da Criança e do Adolescente (1990) e o Código Civil (2002), nos seus artigos $3^{\circ}$ e $4^{\circ}$.

Para Jacques-Alain Miller (1999), a irresponsabilidade

significa que os demais têm direito de responder por alguém, isto é, que se deixa de ser um sujeito de pleno direito. O termo sujeito, portanto, não se introduz a partir do mental, mas a partir do direito. ... É irresponsável quem não pode dar razão a seus atos, quem não pode responder por eles. (p.22)

A questão da responsabilidade e da responsabilização é constitutiva tanto do campo da Psicanálise quanto do campo do Direito. O discurso jurídico, ligado a princípios universais, orientado pela ordem e pelo formalismo do texto da lei, produz um quadro no qual não é dada a palavra ao sujeito, uma vez que articula toda demanda a algo que só pode ser inscrito no vocabulário jurídico.

Em Psicanálise, partimos da noção de que o sujeito deve se responsabilizar por aquilo que causa seu sofrimento. Essa noção de responsabilidade une o sujeito ao seu ato. Lacan (1966/1998b) nos adverte que "por nossa posição de sujeito, sempre somos responsáveis” (p. 873).

Nos primórdios da construção da teoria psicanalítica, Freud (1900/2006a) já abordava a questão da responsabilidade do sujeito:

se olharmos para os desejos inconscientes reduzidos à sua mais fundamental e verdadeira forma, teremos de concluir, fora de dúvida, que a realidade psíquica é uma forma especial de existência que não deve ser confundida com a realidade material. Desse modo, não parece haver justificativa para a relutância das pessoas em aceitar a responsabilidade pela imoralidade de seus sonhos. (p. 658-59)

Ou seja, ali onde o eu não se reconhece, o sujeito deve se responsabilizar. $\mathrm{O}$ discurso psicanalítico visa à responsabilização do sujeito perante o seu próprio discurso. A Psicanálise, então, se dirige ao sujeito de pleno direito, àquele que pode se responsabilizar pelos próprios atos.

Ribeiro (2011) completa a noção de responsabilização partindo do texto Responsabilidade e Resposta, de Laplanche (1999), e argumentando que

antes de pensarmos na responsabilidade das pessoas pelos seus atos. ... deveríamos nos deter sobre as vicissitudes da resposta que uma determinada condição antropológica fundamental nos obriga a dar. A condição prévia para pensarmos sobre a importância e a possibilidade de responder por é o reconhecimento de que algo constitutivo da própria condição humana nos interpela e nos obriga a responder a. (p. 72)

Em outras palavras, não basta fazer eco ao discurso moral contemporâneo de convocar o sujeito a responsabilizar-se por seus atos se não o convocamos também, ao mesmo tempo, a procurar os traços de alteridade em si e fora de si que determinam suas respostas. A responsabilidade não pode ser uma via para o individualismo, para tomar apenas a si mesmo como causa de toda ação moral. Do ponto de vista psicanalítico, a responsabilidade começa quando reconhecemos o papel do outro em nós e sobre nós. É só a partir desse reconhecimento, sempre prioritário, pois constitutivo de nossa própria subjetividade, que podemos responder ao outro.

\section{A Psicanálise e a Lei}

Vale lembrar que o campo jurídico - como o lugar da lei que supostamente visa garantir os interesses dos cidadãos e das cidadãs - possui um discurso universal, não se preocupa com a singularidade dos sujeitos e dirige-se ao que é determinado como dever-ser: "um homem capaz de ser razoável, segundo uma determinada norma" (Cerruti, 2007, p. 119). O campo jurídico estabelece normas no sentido do "dever ser", e aquele que se afasta dessa norma deve receber uma sanção. Esse movimento demonstra o que Freud, em 1930, já afirmava:

Grande parte das lutas da humanidade centralizam-se em torno da tarefa única de encontrar uma acomodação conveniente - isto é, uma acomodação que traga felicidade - entre esta reivindicação do indivíduo (sua satisfação) e as reivindicações culturais do grupo, e um dos problemas que incide sobre o destino da humanidade é o de saber se tal acomodação pode ser alcançada por meio de alguma forma específica de civilização, ou se este conflito é irreconciliável. (Freud, 1930/2006f, p. 116)

Para a Psicanálise, a lei possui várias funções e entra na dinâmica psíquica de cada sujeito de forma particular. De um ponto de vista mais geral, a lei está do lado das instâncias de recalque, isto é, ela nos auxilia a barrar o pulsional, nossos desejos antissociais ou aqueles que não levam em consideração a dignidade do outro enquanto outro. Todavia, a lei também pode servir a outros fins pulsionais. Ela pode ser sádica: mostram isso a história dos regimes totalitários, 
a luta por direitos civis das minorias (excluídos em nome da lei, seja por seu silêncio, seja por sua exclusão direta). Nesse sentido, gostaríamos de repensar uma famosa advertência de Freud: "a Psicanálise não tem como oferecer aos processos jurídicos elementos para o Direito se servir em suas decisões sobre a culpa e o castigo, ou seja, o veredicto do tribunal não deve se apoiar nas investigações da Psicanálise" (Freud, 1906/2006b, p.105).

Freud (1906/2006b) busca separar a Psicanálise do discurso jurídico. Poderíamos pensar no momento histórico em que Freud construiu sua teoria e em alguns pontos de sua obra em que fica claro o seu interesse em se aproximar da ciência positivista que imperava na época. Àquele tempo, nas ciências jurídicas reinava o legado do positivismo, que buscava a definição dos limites do objeto do conhecimento jurídico e se baseava na concepção de que apenas a lei positivada é que deveria ser considerada. Hoje, podemos nos valer dos preceitos pós-positivistas predominantes no Direito, em que é possível a interlocução do Direito com as diversas áreas das Ciências Humanas. Esses preceitos se originaram a partir de um movimento de reação antiformalista iniciado na Europa no final do século XIX chamado de "concepção sociológica do direito", segundo o qual se considera a defasagem entre a lei escrita nos códigos e a realidade social. Esse movimento, que tem enorme importância na história do Direito, dá ênfase à adaptação das leis às necessidades concretas emergentes da sociedade e ao estudo mais profundo da sociedade e do homem baseando-se no diálogo com outras áreas do conhecimento (Bobbio, 2011).

Acreditamos que o "veredicto do tribunal" pode ser enriquecido pelo diálogo com a psicanálise. Certamente, não será nossa prática clínica o único lugar a contribuir para a construção de leis ou a contribuir para com julgamentos. A questão, porém, é que o saber clínico oriundo da Psicanálise também pode servir de base para a reflexão jurídica. Nessa questão específica dos direitos civis das mulheres, a Psicanálise tem muito a contribuir.

\section{Um Exemplo Notável}

Para que se tenha ideia de como o diálogo com as ciências humanas é fundamental não apenas na elaboração da lei como também na sua interpretação e execução, examinemos o discurso do Ministro Ayres Britto (2012), quanto à natureza incondicionada da ação penal nos casos de violência contra as mulheres. $\mathrm{O}$ ministro começa seu discurso citando estudos dos sociólogos Pierre Bourdieu e Gilberto Freyre. Ele lembra que os dois autores concordam que os dominados aplicam o sistema simbólico dos dominadores. O sonho do oprimido, diz Britto, citando Freyre, não é ser opressor de seu opressor, mas dos oprimidos outrora seus companheiros. A agredida tende a condescender com o agressor, pois aceita a imagem que tem de si mesma, tendo sido essa imagem feita pelo próprio sistema de dominação que a agride. Nesse caso, continua o ministro, entre o forte e o fraco, a lei é que liberta, a liberdade é o que escraviza: não se pode deixar apenas à agredida a decisão sobre o destino do agressor. Nesse ponto, a Ministra Carmen Lúcia faz um aparte lembrando que a situação da agredida lembra os casos de Síndrome de
Estocolmo. Britto ainda lembra que a lei protege a agredida dela mesma e conclui com uma curiosa metáfora: a mesma liberdade para lobos e cordeiros é excelente para os lobos.

Notem, nesse breve discurso de dez minutos, como estão presentes as Humanidades como referências simbólicas e legitimadoras do tipo de lei que se propõe. Sociologia, Psicologia (Síndrome de Estocolmo) e Filosofia Moral (a "metáfora dos lobos"). Por que ficaria de fora a Psicanálise? Talvez porque ela insistiria em alguns pontos a fim de desconstruir a lógica desse discurso. $\mathrm{O}$ primeiro deles seria lembrar que Bourdieu provavelmente jamais defenderia tal lógica de apropriação de suas ideias sobre a dominação masculina (Bourdieu, 2005). O fato de o dominado reproduzir o sistema de dominação sob o qual se encontra subjugado não implica que ele deva ser "protegido". Ao contrário: implica uma crítica ao sistema de dominação e fabricação da subjetividade das mulheres nesses moldes depreciativos da sociedade patriarcal. "Protegê-la" é, mais uma vez, infantilizá-la e dar continuidade ao processo de passividade ao qual as mulheres são submetidas.

A relação binária vítima/agressor reflete o processo de vitimização incorporada pelas atuais políticas públicas de proteção. O ordenamento que gira em torno dessas ações cria um campo em que a vítima se vê privada de condições de refletir sobre a responsabilidade subjetiva que possui nesse processo. Esse ordenamento reproduz fielmente a passividade e reforça o processo de vitimização. Não podemos deixar de considerar as condições históricas que contribuem para a configuração desse cenário. Deve-se comparar o caráter de ação penal pública incondicionada que se aplica à vítima com o que parece ser resultado da estrutura patriarcal do sistema jurídico. É um efeito dessa estrutura o fato de, com relação aos agressores, ainda dependermos da determinação dos juízes para encaminhá-los ou não aos programas de reeducação (Oliveira, 2014).

Em segundo lugar, a Síndrome de Estocolmo é talvez um dos grandes exemplos clínicos de como independe da condição de mulher ou da condição doméstica para que o masoquismo se instale. Além disso, a própria síndrome também desconstrói o argumento de que essa violência gera uma cegueira da vítima devido ao longo tempo de violência. No caso dos sequestrados, a paixão pelo agressor se dá num tempo muito menor. O que está em questão, mais uma vez, é como o masoquismo se instala em cada história pessoal. Afinal, nem todo sequestrado desenvolve a síndrome e nem toda mulher agredida permanece no lugar infantilizado das impotentes. Todavia, nosso contexto sócio-histórico parece facilitar a posição subalterna das mulheres, assim como nosso contexto jurídico, como apontam Campos e Carvalho (2006): "os operadores jurídicos em geral, mas sobretudo os juízes, padecem de profunda falta de capacidade de escuta" (p.420), em especial para as questões de gênero.

Por fim, também é possível criticar a metáfora dos lobos e cordeiros. Em primeiro lugar, sugerindo nunca esquecer de Darwin (1876/1859) nesse diálogo, a natureza nunca precisou de uma lei para proteger os cordeiros ou os animais mais fracos. Eles se protegem como podem e como a seleção natural os dotou ao longo dos tempos. Em segundo lugar, a metáfora é insidiosa, pois naturaliza uma relação social historicamente determinada. Mulheres não são cordeiros e 
homens não são lobos - nem metaforicamente. Laplanche (1999) nos lembra como o adágio “o homem é o lobo do homem" é enganoso, pois recusa que a violência humana é pulsional e não biológica. Nesse sentido, criticamos a leitura do ministro: a passividade não é natural, é histórica e libidinalmente determinada. Trata-se de masoquismo e não de uma semelhança natural com os cordeiros. Belo (2011) nos adverte que o uso de metáforas zoológicas como essas, de forma geral, são artifícios naturalizantes e estão à serviço do recalcamento da plasticidade pulsional, ou seja, dos virtualmente infinitos destinos histórico-libidinais de cada sujeito.

\section{Pode a Subalterna Desejar?}

O problema da mulher aqui abordado pode ser pensado a partir das considerações de Spivak (2012), quando aborda a questão da subalternidade no contexto da produção colonial. Spivak permite organizar a crítica feminista em dois tempos. Primeiro, descortinam-se os discursos e as práticas da vitimização histórica, ligada aos processos de silenciamento e invisibilidade das mulheres. Depois, propõem-se agenciamentos que incluam as condições materiais das mulheres como uma categoria complexa, "contingenciada pelos múltiplos constituintes identitários" (Almeida, 2013, p. 692), como gênero, classe e raça. Valemo-nos da subalternidade como operador crítico a fim de salientarmos a complexidade do lugar ocupado por mulheres agredidas. Tal operador serve para não perder de vista nem as condições sócio-históricas nem as consequências psíquicas (processos de subjetivação) delas decorrentes.

Segundo a autora (Spivak, 2012), "o sujeito subalterno não tem história e não pode falar" e enfatiza que "o sujeito subalterno feminino está ainda mais profundamente na obscuridade" (p. 85). Spivak nos alerta: ninguém pode falar pelo subalterno sem correr o risco de constituir o outro apenas como objeto de conhecimento e não como sujeito legitimado. O que vale para o contexto da produção colonial estudado por Spivak parece-nos válido para a situação das mulheres no Brasil contemporâneo. Pesquisas nacionais têm demonstrado que a violência contra as mulheres está fortemente atrelada à condição de subalternidade. Narvaz (2005) e Narvaz e Koller (2006) mostram como a violência contra as mulheres é, ao mesmo tempo, "parte da violência cotidiana da dominação patriarcal e da violência estrutural da pobreza" (Narvaz, 2005, p. 161). Cunha (2008), por sua vez, demonstra que a subalternidade pode também ser sentida em termos de "dependência emocional" (p. 171) e não apenas em termos de dependência econômica.

A mulher, em posição de subalternidade, é falada, como se estivesse impossibilitada do relato de sua própria história. Fala-se dela como de um sujeito cuja voz não pode ser ouvida. Narvaz e Koller (2006) apontam, como alguns dos fatores desse silenciamento, o desejo de ter uma família, a inexistência de uma rede articulada de apoio à mulher agredida, o desconhecimento de seus direitos civis, a vergonha da violência sofrida. Jong, Sadala e Tanaka (2008) também apontam esses fatores como motivadores de mulheres agredidas não fazerem ou retirarem as queixas que fazem contra seus agressores.

A subalternidade pode ser vista também nos discursos sobre o ritual sati, no qual as viúvas se autossacrificavam na pira funerária de seus maridos. Hoje esse é um ritual proibido, mas, na própria comunidade indiana, falava-se desse ato como voluntário. "As mulheres realmente queriam morrer" (Spivak, 2012, p. 122), dizia-se. Ora, é provável que houvesse mulheres que queriam morrer e outras que não queriam, mesmo se todas se autoimolassem. Tudo isso confirma somente, segundo Spivak (2012), que a mulher não tem voz e que se fala por ela. É possível tomarmos essa análise sobre o ritual sati como exemplo de um dos pressupostos metodológicos da Hermenêutica Crítica, qual seja a de que "o psíquico deixa de ser separado da esfera sociopolítica; na verdade, o desejo pode ser construído socialmente e utilizado pelos controladores do poder para resultados destrutivos e opressivos" (Kincheloe \& McLaren, 2006, p. 284). Apesar de a mulher se colocar como sujeito da ação, a autoimolação é ainda efeito da cultura de violência contra as mulheres.

No caso das mulheres agredidas por seus parceiros amorosos, poder-se-ia pensar na opção dessas mulheres em continuar com seus agressores como ato voluntário. Todavia, devemos também nos perguntar se esse desejo já não seria, por sua vez, uma resposta esperada da mulher. Não é esse o resultado mais exemplar da dominação masculina, isto é, a submissão plena da mulher ao homem que a espanca? Acreditamos que sim e é nesse sentido que sustentamos o pressuposto metodológico de não despolitizar o desejo, tornando-o excessivamente individual, ou tomando a singularidade separada do contexto que lhe tornou possível e que lhe constituiu.

Mais uma vez, diante do que foi exposto, podemos indagar se a transformação da Lei Maria da Penha em ação penal pública incondicionada não poderia se constituir em um modelo de manter a submissão como "modo de ser" da mulher, desta feita, ao "juiz salvador". Do ponto de vista da mulher, poderia haver uma espécie de sublimação aqui: dali onde a violência é claramente sádica e opressora advém a violência-de-salvação, que julga ser capaz de dizer em nome de alguém, adulto, responsável e capaz, a verdade de seu desejo.

Os resultados de pesquisas como as de Spivak (2012), Jong et al. (2008) e Narvaz e Koller (2006) demonstram as enormes dificuldades encontradas pelas mulheres para terem seus direitos civis reconhecidos. "A violência frequente que permeia os relacionamentos no âmbito sócio-econômico e político e reproduz-se no âmbito familiar passa a ser encaradas, nas suas formas menos visíveis, como natural pelas mulheres agredidas pelos companheiros" (Jong et al., 2008, p. 750). Tem-se, assim, a equivocada impressão de que a subalterna, efetivamente, não pode enunciar seu próprio direito, quiçá seu desejo. Contra essa interpretação, temos que fazer um triplo trabalho: (a) devemos melhorar as condições sociais para tornar essa enunciação possível - e a Lei Maria da Penha parece ser uma dessas melhorias; (b) devemos pensar e executar estratégias através das quais as mulheres serão capazes de opor resistência não apenas ao agressor, mas também e principalmente ao seu masoquismo; e (c) criar condições para que os agressores também sejam 
escutados e tratados sob os mais diversos dispositivos psicoterapêuticos de forma a reconhecerem o caráter violento e, nesse sentido, ilegal das agressões dirigidas às mulheres. Os dois últimos trabalhos, isto é, trabalho contra o masoquismo e contra o sadismo, respectivamente, são tarefas para as quais a Psicanálise tem muito a contribuir, na medida em que acreditamos ser uma tarefa que apenas o sujeito pode realizar em seu nome, dadas as condições possíveis para isso acontecer.

\section{Conclusão}

Não se trata, portanto, de desconsiderar a função da Lei Maria da Penha. A lei deve existir. A questão que se coloca é: como essa lei deverá ser aplicada. A violência contra a mulher é um lugar privilegiado de fantasias inconscientes. Isso vale para todos os envolvidos: a mulher, o agressor e o operador jurídico que lidará com o caso. A advertência de Ribeiro (2011) é preciosa:

No âmbito do Direito, onde a questão da condenação e punição da violência se coloca cotidia-namente, é fundamental que se leve em conta que a violência é invariavelmente sexual e que a própria punição estabelecida pela lei pode se tornar um instrumento para o exercício dessa violência sexual. Se para os que são familiarizados com a psicanálise, os imperativos do superego aparecem nitidamente como inseparáveis dos imperativos da pulsão sexual, é preciso que os estudiosos do Direito se deem conta de que a imposição da lei pode se confundir com um meio de satisfação dessas mesmas pulsões. A resposta exigida de cada um ao ataque interno da pulsão sempre poderá influenciar desde a sentença proferida pelo juiz até o tratamento dispensado ao condenado pela carceragem. (p. 72-73)

O operador do Direito - no limite, todos os cidadãos deve ter em mente que, ao aplicar uma lei, está respondendo aos ataques pulsionais supramencionados. As fantasias sadomasoquistas certamente desempenham seu papel na construção das leis, como vimos no exemplo do discurso do Ministro Ayres Britto (2012), quando se articula a posição da mulher à posição do cordeiro frente ao lobo.

Nossa hipótese é que, ao se ter transformado a Lei Maria da Penha em ação penal pública incondicionada, respondese ainda à manutenção da prática ideológico-cultural que aprisiona a mulher como submissa e impotente, passiva e incapaz. Ao defender o masoquismo como posição subjetiva e fruto de uma história libidinal, a Psicanálise não está defendendo que essa posição deva ser legitimada sob essa forma brutal que é a violência contra as mulheres. $\mathrm{O}$ que estamos defendendo é que o masoquismo só poderá ser debelado se criarmos condições sociais, por meio de políticas públicas robustas, fortalecendo as delegacias especiais, os grupos de acolhimento na rede de saúde, para citar apenas dois dispositivos de resistência e emancipação, para permitir que a mulher saia, por conta própria, desse lugar. Para isso, ela certamente não precisa de alguém que fale por ela, mas deverá ser capaz de dizer ali onde, até então, só pode dizer com seu corpo espancado.

\section{Referências}

Almeida, S. R. G. (2013). Intervenções feministas: Pós-colonialismo, poder e subalternidade. Revista Estudos Feministas, 21(2), 689700. Recuperado de http://www.scielo.br/pdf/ref/v21n2/19.pdf.

BBC Brasil. (2011). ONU cita Lei Maria da Penha como pioneira na defesa da mulher. Recuperado de http://www.bbc.co.uk/ portuguese/noticias/2011/07/110706_onu_mulher_relatorio_ rp.shtm.

Belo, F. (2011). O animal na obra de Freud: Uma leitura de O Senhor das Moscas. In J. N. de M. Coutinho, (Org.), Direito e Psicanálise: Interseções e interlocuções a partir de O Senhor das Moscas de William Golding (pp. 245265). Rio de Janeiro: Lumen Juris.

Bitencourt, C. R. (2005). Código penal comentado. São Paulo: Saraiva.

Bobbio, N. (2011) Teoria da norma jurídica (A. B. \& F. P. Batista,

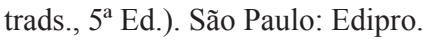

Bourdieu, P. (2005). A dominaçãoo masculina (Maria Helena Kühner, trad., 4a. Ed). Rio de Janeiro: Bertrand Brasil.

Britto, A. Discurso proferido em plenário do STF, em 21/02/2012. Recuperado de http://www.youtube.com/ watch?v=Jpib6avphmg.

Campos, C. H., \& Carvalho, S. (2006). Violência doméstica e Juizados Especiais Criminais: Análise a partir do feminismo e do garantismo. Estudos Feministas, 14(2), 409-422. Recuperado de http://www.scielo.br/pdf/ref/v14n2/a05v14n2. pdf.

Carvalho, A. C. (2012). O papel da psicanálise no rebaixamento do feminino. In O feminino: Diversos olhares (pp. 12-20). Belo Horizonte: CRP04.

Cerruti, M. Q. (2007). Bate-se em uma mulher: Os impasses da vitimização. Dissertação de Mestrado, Instituto de Psicologia, Universidade de São Paulo, São Paulo.

Cunha, T. R. (2008). Violência conjugal: Os ricos também batem. UEPG: Ciências Humanas, Linguística e Artes, 16, 167-176. Recuperado de http://www.revistas2.uepg.br/index.php/ humanas/article/view/628.

Darwin, C. (1876). On the origin of species by means of natural selection or the preservation of favored races in the struggle for life (6th ed.). London: Murray. (Original publicado em 1859)

Freud, S. (2006a). Interpretação dos sonhos. In Edição standard brasileira das obras psicológicas completas de Sigmund Freud (W. I. de Oliveira, trad., Vol. 5, pp. 371- 648). Rio de Janeiro: Imago. (Original publicado em 1900)

Freud, S. (2006b). A psicanálise e a determinação dos fatos nos processos jurídicos. In Edição standard brasileira das obras psicológicas completas de Sigmund Freud. (M. A. M. Rego, trad., Vol. 9, pp. 91-104). Rio de Janeiro: Imago. (Original publicado em 1906)

Freud, S. (2006c). O problema econômico do masoquismo. In Edição standard brasileira das obras psicológicas completas de Sigmund Freud (E. A. M. de Souza, trad., Vol. 19., pp. 175188). Rio de Janeiro: Imago. (Original publicado em 1924)

Freud, S. (2006d). A dissolução do complexo de Édipo. In Edição standard brasileira das obras psicológicas completas de Sigmund Freud (E. A. M. de Souza, trad., Vol. 19, pp. 191-199). Rio de Janeiro: Imago. (Original publicado em 1924) 
Freud, S. (2006e). Algumas consequências psíquicas da distinção anatômica dos sexos. In Edição standard brasileira das obras psicológicas completas de Sigmund Freud (E. A. M. de Souza, trad., Vol. 19, pp. 271- 286). Rio de Janeiro: Imago. (Original publicado em 1925)

Freud, S (2006f). O mal estar na civilização. In Edição standard brasileira das obras psicológicas completas de Sigmund Freud (J. O. de A. Abreu, trad., Vol. 21, pp. 67- 148). Rio de Janeiro: Imago. (Original publicado em 1930)

Freud, S (2006g). Conferência XXXIII: Feminilidade. In Edição standard brasileira das obras psicológicas completas de Sigmund Freud (J. L. Meurer, trad., Vol. 22, pp. 113-134). Rio de Janeiro: Imago. (Original publicado em 1933)

Fundação Perseu Abramo. (2011). Violência doméstica. Recuperado de http://novo.fpabramo.org.br/content/violencia-domestica.

Kehl, M. R. (2008). Deslocamentos do feminino. Rio de Janeiro: Imago.

Kehl, M. R. (2013). O peso da feminilidade. Recuperado de http:// www.mariaritakehl.psc.br/PDF/opesodafeminilidade.pdf.

Kincheloe, J., \& McLaren, P. (2006) Repensando a teoria crítica e a pesquisa qualitativa. In Denzin, N., Lincoln, Y. Orgs.), $O$ planejamento da pesquisa qualitativa: Teorias e abordagens (S. R. Netz, trad.). Porto Alegre: Artmed.

Jong, L., Sadala, M., \& Tanaka, A. (2008). Desistindo da denúncia ao agressor: Relato de mulheres vítimas de violência doméstica. Revista Escola de Enfermagem USP, 42(4), 744751. Recuperado de http://www.scielo.br/pdf/reeusp/v42n4/ v42n4a17.pdf.

Lacan, J. (1998b). A ciência e a verdade. In Escritos. (V. Ribeiro, trad., 869-892). Rio de Janeiro: Zahar. (Original publicado em 1966)

Laplanche, J. (1999). Résponsabilité et réponse. In Entre seduction et inspiration: L'homme. (pp. 147-172). Paris: Quadrige/PUF.

Lei Federal n. 3.071, de $1^{\circ}$ de Janeiro de 1916. (1916). Recuperado de http://www.planalto.gov.br/ccivil_03/leis/L3071impressao. htm.

Lei Federal n. 8069, de 13 de julho de 1990. (1990).

Lei Federal n. 10.406, de 10 de Janeiro de 2002. (2002).
Lei Federal n. 11.340, de 7 de agosto de 2006. (2006). Recuperado de http://www.planalto.gov.br/ccivil_03/_ato2004-2006/2006/ lei/111340.htm.

Miller, J. A. (1999). Saúde Mental e Ordem Pública. Curinga, 13, pp. $14-24$.

Narvaz, M. (2005). Submissão e resistência: Explodindo o discurso patriarcal da dominação feminina. Dissertação de mestrado não-publicada, Programa de Pós-graduação em Psicologia do Desenvolvimento, Universidade Federal do Rio Grande do Sul, Porto Alegre. Recuperado de http://www.lume.ufrgs.br/ handle/10183/5442.

Narvaz, M., \& Koller, S. (2006). Mulheres vítimas de violência doméstica: Compreendendo subjetividades assujeitadas. Psico, 37, 7-13. Recuperado de http://revistaseletronicas.pucrs.br/fo/ ojs/index.php/revistapsico/article/view/1405/1105.

Oliveira, É. C. S. (2014). Contando estórias e inventando metodologias para discutir a violência contra as mulheres. Estudos Feministas, 22(1), 195-214. Recuperado de http:// www.scielo.br/pdf/ref/v22n1/11.pdf.

Penna, P. D. M. \& Leão, S. (2014). Em briga de marido e mulher, o Estado deve meter a colher? Transfinitos, 12, 297-307.

Perrot, M. (2005) As Mulheres ou os silêncios da história (V. Ribeiro, trad.). Bauru: EDUSC.

Ribeiro, P. C. (2011). Alteridade, inconsciente e direito: Possessão demoníaca ou estrutura da linguagem? Homens ou normas fundamentais? In III Congresso Nacional de Psicanálise, Direito e Literatura: responsabilidade e resposta. Recuperado de http://conpdl.com.br/conpdl3 anais.pdf.

Spivak, G. (2012). Pode o subalterno falar? (S. R. G. Almeida, M. P. Feitosa, \& A. P. Feitosa. trads.), Belo Horizonte: UFMG. (Original publicado em 1982)

Supremo Tribunal Federal. Supremo julga procedente ação da PGR sobre Lei Maria da Penha. Recuperado de http://www.stf.jus. $\mathrm{br} /$ portal/cms/verNoticiaDetalhe.asp?idConteudo=199853.

Recebido em 27.08.2014

Primeira decisão editorial em 21.10.2014

Versão final em 30.06.2015

Aceito em 30.06.2015 